\title{
Research
}

\section{Understanding the management of early-stage chronic kidney disease in primary care:}

\author{
a qualitative study
}

\begin{abstract}
Background

Primary care is recognised to have an important role in the delivery of care for people with chronic kidney disease (CKD). However, there is evidence that CKD management is currently suboptimal, with a range of practitioner concerns about its management
\end{abstract}

\section{Aim}

To explore processes underpinning the implementation of CKD management in primary care.

\section{Design and setting}

Qualitative study in general practices participating in a chronic kidney disease collaborative undertaken as part of the National Institute for Health Research (NIHR) Collaboration for Leadership in Applied Health Research and Care (CLAHRC) for Greater Manchester.

\section{Method}

Semi-structured interviews were conducted with GPs and practice nurses $(n=21)$. Normalisation Process Theory provided a framework for generation and analysis of the data.

\section{Results}

A predominant theme was anxiety about the disclosure of early-stage CKD with patients. The tensions experienced related to identifying and discussing CKD in older people and patients with stage 3A, embedding early-stage CKD within vascular care, and the distribution of work within the practice team. Participants provided accounts of work undertaken to resolve the difficulties encountered, with efforts having tended to focus on reassuring patients. Analysis also highlighted how anxiety surrounding disclosure influenced, and was shaped by, the organisation of care for people with CKD and associated long-term conditions.

\section{Conclusion}

Offering reassurance alone may be of limited benefit, and current management of early-stage CKD in primary care may miss opportunities to address susceptibility to kidney injury, improve self-management of vascular conditions, and improve the management of multimorbidity.

\section{Keywords}

doctor-patient relations; kidney disease, chronic; normalisation process theory; primary care.

\section{INTRODUCTION}

Primary care is recognised to have an increasingly important role in identifying and managing people with chronic kidney disease (CKD).1,2 This is reflected in national strategies including the introduction of renal domains within the Quality and Outcomes Framework (QOF) of the new general medical services contract. ${ }^{3}$ Since 2006 general practices have been remunerated for maintaining a register and providing evidence-based care for individuals with CKD stages 3-5 (Box 1). ${ }^{3}$ Recommendations focus on reducing the frequency of cardiovascular events and progression to established renal failure for people with CKD (that is, stage 5). ${ }^{1-3}$

Approximately $5-6 \%$ of the population has stage 3 to stage $5 \mathrm{CKD}$, with a higher prevalence in older people and more socially-deprived communities. ${ }^{3}$ It is estimated that around $50 \%$ of females over 75 years and $50 \%$ of males over 85 years have stage 3 to stage 5 CKD. ${ }^{4}$ While renal function is recognised to decline with age, it is considered that this decline arises in the context of vascular comorbidities, which are common in older people, rather than as a consequence of the ageing process per se'. ${ }^{4}$ As such, although controversy exists as to

T Blakeman, PhD, MRCGP, NIHR clinical lecture in primary care; $\mathbf{A}$ Rogers, $\mathrm{PhD}$, professor of the sociology of health care; $\mathbf{A}$ Kennedy, PhD, senior research fellow, The University of Manchester, Health Sciences Research Group, and

Collaboration for Leadership in Applied Health Research and Care (CLAHRC) for Greater Manchester, School for Community Based Medicine, University of Manchester, Manchester. J Protheroe, PhD, MRCGP, senior lecturer in general practice, The University of Keele, NIHR School for Primary Care Research, Institute of Primary Care and Health Sciences, Keele, Staffordshire. C Chew-Graham, MD, FRCGP, professor of primary care, NIHR School for Primary Care Research, The University of Manchester, Manchester whether it is a 'normal' ageing process for patients with stage $3 A C K D$, it is recommended that age alone should not preclude patients being managed according to National Institute for Health and Clinical Excellence (NICE) guidelines. ${ }^{1,3,4}$

At present, there is evidence that a large proportion of people with CKD are undiagnosed and that management is suboptimal, with evidence to suggest that practitioners do not currently readily accept national guidelines. ${ }^{5-7} \mathrm{~A}$ range of concerns have been raised by GPs, including difficulties associated with: assigning a diagnosis; the stigmatising effect of a diagnosis; explaining the concept of CKD to patients; achieving blood pressure targets; complicated medication regimens; and uncertainty about referral to secondary care. ${ }^{8}$

The introduction of guidelines for the management of CKD requires a considerable change in behaviour by primary care clinicians. Changing professional behaviour is recognised as difficult and addressing the implementation gap requires an understanding of the reasons for resistance to change, and facilitators of change. ${ }^{9-11}$ With a focus on understanding dialogue around early-stage CKD, particularly stage 3 , this study built on

\section{Address for correspondence}

Tom Blakeman, The University of Manchester NIHR Collaboration for Leadership in Applied Health Research (CLARHC) for Greater Manchester, School of Community Based Medicine, Health Sciences, Primary Care Research Group, Williamson Building, Oxford Road, The University of Manchester, Manchester, M13 9PL.

E-mail: tom.blakemandmanchester.ac.uk

Submitted: 3 October 2011; Editor's response: 19 October 2011; final acceptance: 1 December 2011.

CBritish Journal of General Practice

This is the full-length article (published online 26 Mar 2012) of an abridged version published in print. Cite this article as: Br J Gen Pract 2012; DOI: 10.3399/bjgp12X636056. 


\section{How this fits in}

Although seen as a priority, GPs and practice nurses have previously expressed a range of concerns about CKD and its management in primary care. Using Normalisation Process Theory as a framework, the research sought to understand the work surrounding the implementation of this relatively new disease classification into clinical practice. The study identified tensions experienced in discussing early-stage CKD with patients. Analysis suggested anxiety surrounding disclosure influenced, and was shaped by, the organisation of care for people with long-term conditions. These tensions need to be considered when developing interventions to improve the delivery of care for people with mild and moderately low kidney function

initial themes raised by Crinson et $a^{\beta}$ and sought to identify processes underpinning the implementation of CKD management in primary care.

\section{METHOD}

\section{Study design}

Normalisation Process Theory (NPT) provided a framework for generation and analysis of the data. ${ }^{12,13}$ NPT is a theory of social action that is concerned with understanding what people do rather than their attitudes or beliefs. ${ }^{13}$ It offers a structure for understanding the processes underpinning care, which enable or constrain the embedding and integration of a set of practices into routine care. As such, through discussion within the research team, NPT was identified as a relevant theory to understand the work surrounding the implementation of a new disease classification into primary care.

\section{Sampling}

In order to explore the implementation of CKD management in primary care, the research purposively sampled the 19 general practices participating in a renal collaborative project established by the Collaboration for Leadership in Applied Health Research and Care (CLAHRC) for Greater Manchester. ${ }^{14}$ The aim of the CKD Collaborative was to halve the gap between the recorded and expected prevalence and ensure patients had blood pressures managed according to NICE-recommended targets. ${ }^{14}$ In order to provide comparisons of the work being carried out, both GPs and practice nurses directly involved in the CKD Collaborative were invited to be interviewed. In addition, to understand how the implementation of CKD management had been operationalised within the wider practice team, GPs working in these practices but not directly involved in the CKD Collaborative were also invited to participate. In doing so, the study aimed to generate a set of accounts from within each practice (that is, matched interviews). Finally, to explore wider contextual issues, a GP acting as primary care lead for renal services in the locality was also invited.

\section{Data collection}

In total, 21 out of the 28 health professionals $(75 \%)$ invited agreed to participate. The final sample was spread across 11 practices and comprised 11 GPs (six male, five female; median age 45 years [range $30-62$ years]) and 10 nurses lall female; median age 47.5 years [range 39-60 years]). Eighteen out of the 21 participants were directly involved in the CLAHRC CKD collaborative. Semi-structured interviews were conducted with participants, at their surgeries, between November 2010 and February 2011. The interviews were carried out by two of the authors and lasted approximately 1 hour (median 52 minutes; range 27-103 minutes). The interviews were audiotaped and professionally transcribed. Informed by NPT, the interviews focused on generating accounts of the lindividual and collectivel work concerning the management of early-stage CKD. This included exploring different types and levels

\section{Box 1. How is chronic kidney disease (CKD) classified?3}

CKD is divided into five stages based on estimated glomerular filtration rate (eGFR) according to the Kidney Disease Outcomes Quality Initiative (K-DOQI) classification.

A minimum of two eGFR values at least 3 months apart should be used to diagnose and classify CKD temporary rises in creatinine are common and a diagnosis of progressive CKD should only be based on a sustained decline in renal function. People with an eGFR of $60 \mathrm{~mL} / \mathrm{min} / 1.73 \mathrm{~m}^{2}$ or over should not be considered to have CKD unless there is other evidence of kidney damage.

In stage 1 and stage 2, other markers of kidney damage are required for a diagnosis of CKD. These markers can either be on imaging (for example, polycystic kidneys) or abnormal urine findings (for example, microalbuminuria, proteinuria or microscopic haematurial. 
of work during consultations, within practices, and links with other services (Table 1).

\section{Data analysis}

NPT was used to sensitise the analysis to the work being carried out in primary care. ${ }^{13}$ Initial coding of the data was undertaken independently by three of the authors and categories were identified by comparing these codes. Through discussion, these categories were seen to relate to three sets of practices around CKD: identifying CKD, disclosing CKD, and managing CKD. Informed by published work describing NPT, a coding framework was then designed that related to the core constructs of the theory (Table 2). ${ }^{11,12,15}$ NPT divides action up according to four constructs: coherence (that is, sense making work); cognitive participation (relationship work); collective action (enacting work); and reflexive monitoring (appraisal work). ${ }^{12,13}$ As stated by the authors of the theory, each construct represents different kinds of work that people do as they work around a set of practices'. ${ }^{13}$ Using the coding framework to help operationalise the theory, these constructs were applied to the sets of practices outlined above, concerning the management of CKD in primary care. The coding framework assisted comparative analysis of data from each individual account, matched interviews, and across the dataset.

In summary, using NPT as a framework, the study constructed an understanding of how early-stage CKD is encountered and dealt with in general practice.

\section{RESULTS}

Viewed as a relatively new condition in clinical practice, participants expressed tensions in managing early-stage CKD in primary care.

A common theme across GP and nurse accounts was anxiety surrounding the disclosure of CKD with patients. The tensions underpinning care related to identifying and discussing CKD in older people and patients with stage $3 \mathrm{~A}$, embedding early-stage CKD within vascular care, and the distribution of work within the practice team.

Tension 1: identifying and discussing CKD in older people and patients with stage $3 \mathrm{~A}$ Reflecting the purpose of the CLAHRC collaborative project, all participants described a shift to actively identifying and coding CKD. This included all adult patients identified by an estimated glomerular filtration rate (eGFR) $<60 \mathrm{ml} / \mathrm{min} / 1.73 \mathrm{~m}^{2}$, irrespective of age, being added to a practice's CKD register:

So the first thing was really to validate our register of CKD ... And we had a huge jump of patients on the register, because we inhouse had actually [previously] decided that all patients over the age of 80 would not be on the register. That this was a progressive natural deterioration, physiological deterioration in kidney function, so we wouldn't actually put them on the register because that meant more work. To get your points of course, you had to do the necessary test that linked in with QOF. But after we had been on the collaborative, of course, one of the first sessions was that really everybody regardless of age should go on. So this is where the big jump was in our prevalence of CKD.' (GP02)

However, this shift in activity created a dilemma about whether and how to discuss these findings, particularly with older people and those with mild renal impairment:

I mean I think that's the issue, because I suppose CKD in an eighty year old, you've got an eGFR of $59\left(\mathrm{ml} / \mathrm{min} / 1.73 \mathrm{~m}^{2}\right)$, is that really CKD or is that just you are 89. I think certainly where I would hope the others have discussed, certainly I am, is ... if you've got CKD or you're young and you've got proteinuria, definitely that is a really important thing to hammer in. But yeah, 80/90 year olds, I wouldn't suggest we're probably discussing it, if they've got a mild CKD3.' (GP06)

For most, despite endeavours to identify and code CKD, there was uncertainty on the merits of disclosure, with a need to 'underplay' CKD in order to avoid frightening patients. In the main, participants described a move to inform patients of early-stage CKD with efforts focused on reassurance. This included reference to it being a normal part of ageing:

I try and reassure them at the beginning that there isn't anything actually to worry about, because they think they've got another new condition. So I explain that we're looking at kidneys much more and it's recognised that they've got more to do with heart disease and blood pressure and what have you and that we're just monitoring ... But just to let them know, I feel that they should know that they're on a register and tell them not to worry. If there's anything to worry about we'll let them know.' (nurse 11) 


\section{Table 1. Topic guide for professional chronic kidney disease (CKD) interviews}

\section{Question} CKD

- Can I ask you how CKD is managed in the practice?

- How do you manage a diagnosis of CKD

-What issues do you feel are the most important for people with CKD?

- How is it discussed in consultations?

- (What is your understanding of CKD?)

- Is CKD something that is brought up in consultations?

- Can I ask how is it brought up?

- How are people with CKD followed-up?

- Can I ask what do you think about the QOF register for CKD?

- How is CKD discussed (a) in the practice (e.g. meetings, with other colleagues); (b) in consultations?

- Is CKD something that is discussed? What gets discussed?

If not, are there any reasons for this?

- Do you have links with specialist services for people with CKD?

- Are there any specific recommendations/guidance that the practice has used in the management of people with CKD?

How do you find these recommendations? How has the model/interventions changed practice, the day-to-day management; consultations?

- Is there anything that you feel helps/hinders care?

- How is CKD linked to other priorities around vascular care?

- Links to vascular disease: what do you feel are the key issues in the (a) management of people with vascular disease and (b) CKD

\section{Vascular work}

- How are people coming in for vascular reviews (such as CHD, blood pressure, stroke) managed in your practice?

-What do you feel are the key issues in the management of people with vascular disease?

-Who is involved in the management of people with vascular conditions?

- How does discussion around CKD compare with discussion about other clinical parameters such as hypertension, cholesterol, glycaemic control?

\section{Multimorbidity work}

- How are people with multimorbidities including CKD managed in

(a) the practice; (b) your consultations?

- How does the management of CKD relate to the management of somebody

with (a) high blood pressure; (b) heart failure; (c) diabetes; (d) other morbidity?

\section{Illness work}

-What do you see as the role of the practice in supporting people in living with

(a) vascular conditions; (b) CKD?

- How do people with (a) vascular conditions; (b) CKD navigate their care?

-What would you want an information resource to look like?

- How would it help with the disclosure of CKD?

\section{Demographics}

- Age

- Practice size

- Training practice

- Nurse title (practice nurse, nurse practitioner, etc)

- Disease-management clinics (if so, what)

$C H D=$ coronary heart disease. $C K D=$ chronic kidney disease

\section{Prompts}

- Do you mind running through how it works, what happens?

- How are people with CKD identified?

- What happens next?

- Are there any examples? Have you recently seen anybody with a diagnosis of early-stage CKD

- Is there a practice view on management CKD disclosure - or any differences in practitioners?

- Is it possible to know/how do you know what other people are doing in the practice?

- How do you think others (in/outside practice) view the management of CKD?

- Do you always tell patients they have the diagnosis. If yes - how do you tell? If no how do you decide who to tell? What criteria: who is this discussed with - in the practice, as a team, individual practice ... others

-What is the role of the computers in managing people with (a) vascular conditions; (b) CKD?

- Are there benefits for patients to being on the register?

- Do patients always know they are on a register?

-What is the role of (insert type of professional) in the management of people with (a) vascular conditions; (b) CKD?

- healthcare assistant

- GPS

- other fellow GPs

- practice nurse

- reception staff

- IT

- practice manager

- health trainer

-What tends to be discussed in consultations with people who have (a) vascular conditions; (b) CKD; (c) other comorbidities?

-What happens in your consultations?

-What is the role of (insert type of professionall in the management of people with (a) vascular conditions; (b) CKD?

- How has care for people with (a) vascular conditions; (b) CKD changed over time?

- Is it possible to know/how do you know what other people are doing in the practice?
And I'll say to them if I was 88 I'd expect my kidneys might be a bit under par as well, and that's sometimes how / would reassure people who are just very marginally in and fairly stable at that sort of level.' (GP0802)
Some clinicians described a shift in how CKD in older people was viewed, with increasing awareness of a patient's renal function and of taking this into account when determining an individual's overall health. 
Table 2. Normalisation process theory coding frame for the management of chronic kidney disease in primary care ${ }^{11,12,15}$

\begin{tabular}{|c|c|c|c|}
\hline $\begin{array}{l}\text { Coherence } \\
\text { (Sense-making work) }\end{array}$ & $\begin{array}{l}\text { Cognitive participation } \\
\text { (Relationship work) }^{\mathrm{b}}\end{array}$ & $\begin{array}{l}\text { Collective action } \\
\text { (Enacting work) }{ }^{c}\end{array}$ & $\begin{array}{l}\text { Reflexive monitoring } \\
\text { (Appraising work)d }^{\text {d }}\end{array}$ \\
\hline Differentiation & Enrolment & Interactional workability & Reconfiguration \\
\hline Defining, dividing up, and categorising task & Recruiting the self and others to tasks & $\begin{array}{l}\text { Doing tasks, and making outcomes, } \\
\text { in practice }\end{array}$ & Changing tasks \\
\hline $\begin{array}{l}\text { Are staff within an organisation clear on } \\
\text { their roles regarding a particular task? } \\
\text { Are staff within an organisation clear on } \\
\text { others roles regarding a particular task? }\end{array}$ & $\begin{array}{l}\text { Do participants engage with other staff } \\
\text { around a particular task? } \\
\text { Who initiates the engagement? } \\
\text { Who does and who does not } \\
\text { buy-in' to a particular task? }\end{array}$ & $\begin{array}{l}\text { How is a particular task/practice } \\
\text { le.g. disclosing CKDl enacted } \\
\text { in consultations? } \\
\text { How is a particular task brought } \\
\text { into view? } \\
\text { How does a particular task fit with } \\
\text { existing work? How have patients } \\
\text { and professionals adapted to the } \\
\text { introduction of a particular practice? } \\
\text { What effect does a particular task } \\
\text { have on consultations? } \\
\text { How does the task/practice affect } \\
\text { patient and professional contribution } \\
\text { to dialogue? }\end{array}$ & $\begin{array}{l}\text { Has a particular task/practice been } \\
\text { adapted based on experience? If so, how? }\end{array}$ \\
\hline Individual Specification & Initiation & Relational integration & Individual appraisal \\
\hline Making sense of personal versions of tasks & $\begin{array}{l}\text { Organising an individual contribution } \\
\text { to tasks }\end{array}$ & $\begin{array}{l}\text { Making and communicating reliable } \\
\text { knowledge about tasks }\end{array}$ & $\begin{array}{l}\text { Individual evaluation of contributions } \\
\text { and tasks }\end{array}$ \\
\hline $\begin{array}{l}\text { Does a participant know what the } \\
\text { task/practice is? } \\
\text { Is the task easy to describe? } \\
\text { What benefits does a task/practice } \\
\text { bring and to whom }\end{array}$ & $\begin{array}{l}\text { What organisational skills does a } \\
\text { participant use to contribute to a } \\
\text { particular task? (e.g. identifying CKD) } \\
\text { Who actively engages with a } \\
\text { particular task? } \\
\text { Are individuals prepared to invest time, } \\
\text { energy and work into a particular } \\
\text { practice? If so, what is this work? }\end{array}$ & $\begin{array}{l}\text { How does a particular practice/task } \\
\text { (e.g. disclosing CKDl affect trust and } \\
\text { confidence between parties } \\
\text { (i.e. patients and professionals)? } \\
\text { How does a particular practice affect } \\
\text { the patient-professional relationship? } \\
\text { How do individuals/parties work to } \\
\text { enact a particular practice and } \\
\text { maintain a relationship? }\end{array}$ & $\begin{array}{l}\text { Is it clear what effects a particular practice } \\
\text { (e.g. identifying CKDI has had? } \\
\text { Do individuals make efforts to reflect } \\
\text { on/appraise a particular task? If so, how? } \\
\text { Has appraisal work informed whether a } \\
\text { ? particular task is advantageous for } \\
\text { patients and staff? }\end{array}$ \\
\hline Communal specification & Activation & Skill set workability & Communal appraisal \\
\hline Making sense of shared versions of tasks & $\begin{array}{l}\text { Organising a shared contribution } \\
\text { to tasks }\end{array}$ & Allocating tasks and performances & $\begin{array}{l}\text { Shared evaluation of contributions } \\
\text { and tasks }\end{array}$ \\
\hline $\begin{array}{l}\text { Do members of staff have a shared sense } \\
\text { of purpose around a task? (GPs, nurses, } \\
\text { reception staff, PM)? } \\
\text { Who thinks a particular task/practice is a } \\
\text { good idea? Who does not? } \\
\text { Are the benefits of a particular } \\
\text { practice/task (e.g. identifying CKD valued } \\
\text { by all participants? } \\
\text { Does a particular task fit with the overall } \\
\text { goals and activity of an organisation? }\end{array}$ & $\begin{array}{l}\text { Does the practice team undertake work } \\
\text { to arrange a shared contribution to a } \\
\text { particular task? } \\
\text { If so, what is this work? } \\
\text { How does a particular task/practice } \\
\text { (e.g. identifying CKD) feature in practice } \\
\text { meetings? }\end{array}$ & $\begin{array}{l}\text { How is a particular task distributed } \\
\text { within the practice team? } \\
\text { What impact does the introduction of } \\
\text { a practice/set of practices have on } \\
\text { the distribution/division of labour, } \\
\text { resources, power and responsibility? } \\
\text { Is the work being devolved to others? } \\
\text { If so, how and for what reason? } \\
\text { Is there alignment in approach } \\
\text { towards a particular practice } \\
\text { throughout the practice team? } \\
\text { Does the introduction of a particular } \\
\text { practice/task alter the awareness } \\
\text { of the work done by other members } \\
\text { within a practice team? }\end{array}$ & $\begin{array}{l}\text { How does a practice team know that a } \\
\text { particular practice has been carried out? } \\
\text { Do participants contribute/share feedback } \\
\text { about a particular practice le.g. identifying } \\
\text { CKDl with others? If so, what is } \\
\text { discussed? } \\
\text { Has appraisal work informed whether a } \\
\text { particular task is advantageous for } \\
\text { patients and staff? }\end{array}$ \\
\hline Internalisation & Legitimation & Contextual integration & Systematisation \\
\hline Learning how to do tasks in context & Making tasks the right thing to do & $\begin{array}{l}\text { Supporting and resourcing tasks in } \\
\text { their social context }\end{array}$ & $\begin{array}{l}\text { Organising a reliable stock of knowledge } \\
\text { about tasks }\end{array}$ \\
\hline $\begin{array}{l}\text { Is there an understanding of how to learn } \\
\text { to do a task? } \\
\text { Do staff have the time to learn to } \\
\text { understand and carry out a particular } \\
\text { task? }\end{array}$ & $\begin{array}{l}\text { Is there work undertaken to ensure that } \\
\text { a particular task is viewed as the right } \\
\text { thing to do? If so, what is this work? } \\
\text { Do staff have the permission to carry } \\
\text { out a particular task? }\end{array}$ & $\begin{array}{l}\text { How is a particular task (e.g. } \\
\text { identifying CKD) resourced? } \\
\text { Is a particular task compatible with } \\
\text { existing work practices? } \\
\text { How is a particular task/practice } \\
\text { (e.g. disclosing CKD) linked to, and } \\
\text { resourced through, organisational } \\
\text { structures (e.g. clinical information } \\
\text { systems, decision support tools, } \\
\text { practice meetings)? } \\
\text { How does the introduction of a particulc } \\
\text { practice (for example, managing CKD } \\
\text { relationship with existing structures? }\end{array}$ & $\begin{array}{l}\text { Has the organisation developed ways of } \\
\text { keeping up to date with a approaches to } \\
\text { managing a set of practices (e.g. the } \\
\text { management of CKD)? } \\
\text { lar } \\
\text { affect the }\end{array}$ \\
\hline
\end{tabular}


This was seen to help support their clinical decision making around the management of other conditions and improve the management of multimorbidity.

.... then you realise they also have CKD so it gives you the level of awareness. This patient has got ... is up the CKD spectrum and we need to be especially aware of how we intervene with their other morbidities. (GP0702)

If disclosure did occur, it was generally framed in the form of reassurance. However, at the other end of a spectrum of responses, one atypical GP proposed a more proactive approach and suggested that in order to reduce susceptibility to kidney injury, patients, irrespective of age, should carry a card highlighting their level of renal function:

'If you've got CKD $3 A$ at 80 , you need a card. You haven't got a kidney disease, you're vulnerable to something going wrong if somebody gives you the wrong tablets or the wrong drugs, and you need a card - like you've had your platinum card.' (GP05)

\section{Tension 2: embedding early-stage CKD within vascular care}

Participants indicated that the management of vascular risk was more readily discussed with younger patients, those with CKD stage $3 \mathrm{~B}$, or those with pre-existing vascular conditions. However, a key tension for professionals was a need to address vascular risk and 'deflect' progression to renal failure without frightening patients. A common theme was a reticence to use the label of 'CKD':

'So, I try not to panic them ... they don't like this CKD label, which is why I don't tend to dwell on that, perhaps, very much, I tend to just skim over it and then go into the explanation rather than saying each time they come, "oh yes, and you've got CKD, haven't you?". '(GP04)

Rather than referring to CKD as a distinct disease entity, professionals described finding it helpful to refer to CKD as a marker of 'wellbeing', with efforts focused on improving overall cardiovascular health. This was linked to a need for tighter blood pressure control and, for some, an opportunity to introduce lifestyle change:

So I think we focus on maintaining the health as it is, rather than actually saying that if they heard the words "CKD" then I think some patients can initially get panicky ... I think we just think of CKD as a CVD [cardiovascular disease] risk.' (GP09)

I don't call it disease, I call it lack of wellness ... If you say "disease", people get frightened or stressed... What it's showing is a messenger of your lack of wellness and how that changes with age and, if it's worse than it should be, then it's reflecting on your diabetes and hypertension in your lifestyle. That's how / do it.' (GP05)

Overall, analysis indicated that the management of early-stage CKD had become embedded in review appointments for patients with known vascular-related conditions, such as diabetes and ischaemic heart disease:

... all patients get an annual review in their birthday month. And I think you'll find that, that happens in a lot of the practices, you know, whether it be stroke, IHD [ischaemic heart disease], hypertension. Their renal profile is done as part of those annual reviews. And we now have obviously the CKD register within the practice, which is obviously as part of QOF. And those patients have annual reviews now as well, yeah." (nurse 01)

Participants tended to describe a sequential approach to these vascular review appointments, generally undertaken by practice nurses. They were framed as an 'MOT', with accounts indicating that patients had normalised the process of coming in for reviews. This usually entailed an initial focus on patients requesting feedback on recently performed blood and urine tests. The appointments then tended to proceed through a checklist approach, working through a range of parameters. As such, the introduction of renal function was viewed as another parameter to be addressed and was not seen to disrupt the review process that already existed.

With this, there was also evidence to suggest that consultations focused on keeping individual disease-specific parameters under control:

'... when I do a diabetic review? Yeah, yeah, yeah, right. So they bring their little blue book in which is a record book. I check their height, weight, well the weight really, they bring a urine sample in. I dip that for protein obviously and sugar. And then we send it off for an albumin, creatinine ratio. I think that's just standard anyway. Look at the blood tests, make sure they're alright, if their 
HbA1c's [haemoglobin A1c] up, advise them, either increase medication, first of all check that they are complying with their medication because as you know, some of them don't. So that's why their blood tests are all up the shoot but anyway, so do that and then if they haven't been taking their medication, then give them 3 months to sort of take medication, check their HbA1c again, look at their kidney profile, if the GFR's low, then just advise them it's a little bit low, explain why, as l've just done.' (nurse 07)

For some participants, this sequential approach to vascular reviews appeared to be associated with a difficulty in prioritising parameters and results, both in terms of reducing space to discuss early-stage CKD as well as concerns that this might be a disruptive experience for patients:

'I don't think it's intentional. I think it is often because patients come in for the diabetic review, or the CHD review, or the hypertension review, erm, and so you do all the things that you would do for somebody with CKD, but you ... perhaps you just don't actually address it as, "Well you've got this problem as well"... well, no, maybe it does actually because maybe when they've got so many other things, because you know you're doing the monitoring that it would require, I think you're less likely to bring it up ... Like I say, you're more likely to discuss it with somebody who's maybe only got that or perhaps one other thing, you know.' (nurse 10)

... because we're very good at giving them figures and saying," oh look your eGFR's this and your cholesterol this and your HbAlc is this" and they all look at ... they must go out shell shocked sometimes ...' (nurse 04)

\section{Tension 3: the distribution of work within the practice team}

For some professionals, in order to reduce patient anxiety, disclosure was viewed to be a discrete event that should take place during consultations with GPs or nurses. For others, largely based on an awareness of difficult experiences, disclosure was seen as distributed in nature and that a 'whole team approach was required to reduce the anxiety surrounding the management of CKD.

There were also accounts to indicate that uncertainty around management including the meaningfulness of identifying and disclosing early-stage CKD (see tension 1) had led to this activity being delegated to other members of the practice team, particularly practice nurses:
When I have had these consultations with patients, their face changes. You almost feel like you have kind of upset them, and it took a lot of my own energy and training to capture it in that consultation, bring them back and sell it to them to say, "This is no reason for panic", but it always sounded hollow because they still remained anxious for quite a while. And I felt, when I spoke to the other GPs, perhaps that is why they kind of kept delegating it to different people rather than take ownership themselves, whereas they were much more comfortable selling IHD and diabetes.' (GP0702)

There were examples of other situations in which patients (and other practice staff) encountered CKD. These included invitation for renal assessment and review appointments, as well as contact with reception staff to check test results.

There was variation in the extent to which participating GPs and nurses were aware of the content of letters inviting patients to come in for further assessment of their renal profile or to attend for annual vascular review appointments. For some, awareness had been raised following concerns that the wording of letters, including those from hospital appointments, had created anxiety in patients:

'It worries people because they think it's a $C K D$, they think that something very serious is wrong ... because sometimes we do send the test forms out to patients in the post ... I make a request there and it linked a problem ahead and it does say CKD ... so for those people that may not have had that conversation about their kidney function that has alarmed some people... They've phoned reception really and said I've received a letter to say I need a blood test and it says, you know, I've got kidney disease ...' (nurse 1102)

As part of care delivery, patients usually made initial contact via the reception staff to find out their results, which, if necessary, was then followed by an appointment with either a GP or nurse. A few participants described efforts to reduce patient anxiety, which included giving more specific instructions to the reception staff. This included stating if there had been any changes in renal function, whether the patient needed to be seen, who to be seen by, and the level of urgency:

"I would put "slight deterioration please book an appointment with GP". They would tend to be the words I would use for the receptionist to read out. And then I would 
probably give the receptionist an indication of how quickly I wanted to see them ... if you just put "See GP", you find that your appointments are chocker block with people that have just come to see the GP because it says see GP on the results. And there's been no indication of the level of urgency for that ... so if you put see GP at next routine appointment they know then that it's not urgent urgent and they feel content in themselves.' (GP0802)

However, in the main, there was little evidence that the potential for patient anxiety surrounding CKD was actively taken into account when reporting results. Steps taken by health professionals to action results tended to be informed by the clinical information system used by the practice:

So they have a picking list and they can just click on that and then it will appear in the notes ... To come in and see the nurse, like I say, or normal, or tell the patient okay - you know, there's various different things they can pick ... It might say to come in, potassium low, or ... to come in, and repeat, but it doesn't really give the reception staff much to tell the patient other than saying the doctor wants you to have a repeat test ... And then they'll come in and say, "Why have I got to have it done again?". (nurse 10)

\section{Funding}

This project was funded from the NIHR Collaboration for Leadership in Applied Health Research and Care for Greater Manchester.

\section{Ethical approval}

The study was approved by the North-West 7 Research Ethics Committee. REC reference number: 10/H1008/1. R\&D reference number: 2010/056.

\section{Provenance}

Freely submitted; externally peer reviewed.

\section{Competing interests}

The authors have declared no competing interests.

\section{Acknowledgements}

The views expressed in this article are those of the authors and not necessarily those of the NHS, the NIHR, or the Department of Health. Special thanks go to the individuals and general practices for their time and contribution.

\section{Discuss this article}

Contribute and read comments about this article on the Discussion Forum: http://www.rcgp.org.uk/bjgp-discuss
'People tend to pick from the drop down ...' (nurse 1102)

Analysis suggested that vascular review appointments and those concerning CKD tended to be initially framed by patients requesting their test results, with professional efforts subsequently focused on reducing anxiety and on needing to reassure patients (see tensions 1 and 2 ).

'Are my blood results back? That's the big thing, is my blood results back? Yeah ... And they always want to know that everything's alright, when they do the blood pressure, very often I'll do it a couple of times because they've been in the waiting room getting anxious, they walk in and, you know, sometimes they've not, sort of, calmed down, you know, so I usually do the blood pressure two or three times with some patients because they're anxious and it's ... is it alright, you know.' (nurse 02)

\section{DISCUSSION}

\section{Summary}

The study analysis highlighted difficulties experienced by GPs and practice nurses surrounding the disclosure of early-stage
CKD. First, a shift to identify and code earlystage CKD irrespective of patient age had exposed an underlying tension: there was professional concern that discussions may create patient anxiety, particularly in older people and those with CKD stage 3A, in whom clinical benefit was deemed less certain. Second, in order to address concerns about labelling patients with a 'disease' entity, some professionals framed renal function as a marker of wellbeing or vascular risk. However, although this was viewed as a useful strategy, there was some evidence that the structure of vascular review appointments treated risk factors as separate entities. This sequential approach constrained opportunity for dialogue around CKD and reinforced professional concerns about upsetting patients. Third, there was variation in the extent to which anxiety surrounding disclosure of CKD was considered within the practice organisation. Planned or otherwise, there was evidence to suggest that the approach taken to disclosure by health professionals influenced, and was shaped by, the distribution of work with the practice team.

\section{Strengths and limitations}

The study builds on previous findings concerning the disclosure of CKD in primary care. ${ }^{8}$ NPT provided a framework to explore in greater detail the interactional work that occurs in clinical encounters and within an organisation. ${ }^{12,13}$ Practices participating in a CLAHRC CKD Collaborative were purposively sampled, ${ }^{14}$ as this approach provided an opportunity to explore attempts to implement CKD management in primary care. In doing so, the study focused on understanding processes that support or constrain implementation of a relatively new disease classification into everyday clinical practice. The research aimed to be hypothesis generating rather than seeking 'empirical generalisations'.16 Exploring GP and nurse accounts from within practices (that is, matched interviews) allowed the researchers to draw out the tensions involved in disclosure work as a practice team. The authors recognise that further recruitment of health professionals not directly involved in the collaborative, as well as sampling of non-clinical practice staff, may have enhanced understanding of issues surrounding implementation. In addition to generating professional accounts, exploring patients' accounts concerning disclosure of CKD could provide an important comparison. Furthermore, building on this study, observational analysis is also needed to gain greater understanding of how the 
management of CKD is enacted in practice. ${ }^{16}$

\section{Comparison with existing literature}

As described by Armstrong, ${ }^{17}$ general practice has historically played a central role in shaping classification systems, which "both structure and constrain the world they describe'. Professional reticence to disclose CKD may reflect wider concerns that the proliferation of health-related, risk-based discourses contributes to a medicalisation of individuals, in which the body is "continually problematised. ${ }^{18-20}$ In addition, there is evidence that the manner in which diagnostic news is delivered has consequences for the doctor-patient relationship'. ${ }^{21}$ With maintenance of relations as a prime objective, professionals are known to work hard to offer reassurance to patients through strategies that 'shroud the bad or negative aspects and expose the good or positive aspects' of a diagnosis. ${ }^{21,22}$ However, although strategies taken may reassure patients that they have a less severe diagnosis than might have been expected', and that 'a condition is not to worry about', there remains a question on the meaningfulness of dialogue that is limited to reassuring patients. ${ }^{21}$

Analysis also highlighted the need to consider the context in which disclosure of CKD is carried out. There was professional recognition that attending consultations was anxiety provoking for patients, and that 'vascular' review appointments were often framed around a request for test results. However, although efforts during consultations were focused on reducing levels of anxiety, there was variation in the extent to which this was considered by professionals in advance of the consultation (for example, reporting blood tests). Using CKD as an exemplar, the findings contribute to bodies of literature that emphasise a need to understand the distributed nature of medical practice, as well as to understand how anxiety is managed and the social defences that exist within organisational settings. ${ }^{23-27}$

\section{Implications for practice and research}

Recognising the limitations of this empirical study (outlined above), the findings from the research suggest that the current approach and structure to management of early-stage CKD in primary care may miss opportunities to address susceptibility to renal damage, ${ }^{28}$ improve self-management of vascular conditions, ${ }^{29}$ and improve the management of multimorbidity. 30,31 For instance, in the study analysis, there was professional uncertainty surrounding the merits of disclosing CKD to older people and those with mild renal impairment (that is, CKD 3A). Increasing patient awareness and participation by focusing on the prevention of acute kidney injury may offer a more meaningful and less disruptive approach to dialogue for professionals and this group of patients. ${ }^{28,32,33}$ There is recognition that patients with early-stage CKD3A are more prone to acute kidney injury, which is associated with significant levels of morbidity and mortality. ${ }^{28,32}$ However, although there is some guidance on prevention in hospital settings, currently there is limited evidence on the role of prevention in primary care. . $8,32^{2}$

This study sought to understand the work undertaken by GPs and practice nurses in implementing a relatively new phenomenon into general practice. The findings highlight tensions experienced by professionals surrounding the management of individuals with early-stage CKD. These tensions need to be considered when developing interventions to improve the delivery of care for people with mild and moderately "low kidney function, ${ }^{20}$ vascular conditions, or multimorbidity. 


\section{REFERENCES}

1. National Institute for Health and Clinical Excellence. Chronic kidney disease. Early identification and management of chronic kidney disease in adults in primary and secondary care (CG73). London: NICE, 2008.

2. Department of Health. The National Service Framework for Renal Services. Part two: chronic kidney disease, acute renal failure and end of life care. London: Department of Health, 2005.

3. De Lusignan S, Gallagher H, Stevens $\mathrm{P}$, et al. Chronic kidney disease frequently asked questions. London: NHS Employers and BMA, 2011, http://www.nhsemployers.org/SiteCollectionDocuments/Chronic_kidney_dise ase_FAQs\%20-\%20ja040711.pdf (accessed 16 Feb 2012).

4. De Lusignan S, Gallagher H, Stevens P, et al. Chronic kidney disease frequently asked questions. London: NHS Employers and BMA, 2009.

5. De Lusignan S, Gallagher H, Chan T, et al. The QICKD study protocol: a cluster randomised trial to compare quality improvement interventions to lower systolic BP in chronic kidney disease (CKD) in primary care. Implement Sci 2009; 4: 39

6. Stevens PE, O'Donoghue DJ, de Lusignan S, et al. Chronic kidney disease management in the United Kingdom: NEOERICA project results. Kidney Int 2007; 72(1): 92-99.

7. Phillips LA, Donovan KL, Phillips AO. Renal quality outcomes framework and eGFR: impact on secondary care. QJM 2009; 102(6): 415-423.

8. Crinson I, Gallagher H, Thomas N, de Lusignan S. How ready is general practice to improve quality in chronic kidney disease? A diagnostic analysis. Br J Gen Pract 2010; 60(575): 403-409.

9. The Academy of Medical Sciences. Research in general practice: bringing innovation into patient care - Workshop report. London: The Academy of Medical Sciences, 2009.

10. Craig P, Dieppe P, Macintyre S, et al. Developing and evaluating complex interventions: new guidance. London: Medical Research Council, 2008.

11. Murray E, Treweek S, Pope C, et al. Normalisation process theory: a framework for developing, evaluating and implementing complex interventions. BMC Med 2010; 8: 63

12. May C, Finch T. Implementing, embedding and integrating practices: an outline of normalization process theory. Sociology 2009; 43: 535-554.

13. May C, Murray E, Finch T, et al. Normalization process theory on-line users manual and toolkit. NPT, 2010. http://normalizationprocess.org laccessed 16 Feb 2012).

14. National Institute for Health Research, Collaboration for Leadership in Applied Health Research and Care (CLAHRC) for Greater Manchester. The CLAHRC Chronic Kidney Disease Collaborative: improving care for people with chronic kidney disease: report on phase 1 of the CKD Collaborative (September 2009-September 2010). Manchester: CLAHRC, 2010. http://clahrc-gm.nihr.ac.uk/projects/implementation/chronic-kidneydisease\#phase1 laccessed 16 Feb 2012).

15. Gallagher K, May CR, Montori VM, Mair FS. Understanding patients experiences of treatment burden in chronic heart failure: using normalization process theory. Ann Fam Med 2011; 9(3): 235-243.

16. Murphy E, Dingwall R, Greatbatch D, et al. Qualitative research methods in health technology assessment: a review of the literature. Health Technol Assess 1998; 2(16): iii-ix, 1-274

17. Armstrong D. Diagnosis and nosology in primary care. Soc Sci Med 2011; 73(6): 801-807

18. Williams S. Chronic illness as biographical disruption or biographical disruption as chronic illness? Reflections on a core concept. Sociol Health Illn 2000; 22(1): 40-67.

19. Spence D. Bad medicine: chronic kidney disease. BMJ 2010; 340: c3188.

20. Clase CM, Garg AX, Kiberd BA. Classifying kidney problems: can we avoid framing risks as diseases? BMJ 2004; 329(7471): 912-915.

21. Maynard DW. 'Does it mean I'm gonna die?': on meaning assessment in the delivery of diagnostic news. Soc Sci Med 2006; 62(8): 1902-1916.

22. Heritage J, Maynard DW. Problems and prospects in the study of physician-patient interaction: 30 years of research. Annu Rev Sociol 2006; 32: 351-374.

23. Rapley T. Distributed decision making: the anatomy of decisions-in-action. Sociol Health Illn 2008; 30(3): 429-444.

24. Mol A. The body multiple: ontology in medical practice. Durham: Duke University Press, 2002

25. Menzies IEP. A case-study in the functioning of social systems as a defence against anxiety: a report on a study of the nursing service of a general hospital. Hum Relat 1960; 13: 95-121.

26. McDonald R, Rogers A, Macdonald W. Dependence and identity: nurses and chronic conditions in a primary care setting. $J$ Health Organ Manag 2008; 22(3): 294-308

27. Krantz J. Social defences and twenty-first century Organizations. $\mathrm{Br} \mathrm{J}$ Psychother 2010; 26(2): 192-201.

28. Lewington A, Kanagasundaram S. Clinical practice guidelines: acute kidney injury. Petersfiend: The Renal Association, 2011. http://www.renal.org/Clinical/GuidelinesSection/AcuteKidneylnjury.aspx (accessed 16 Feb 2012).

29. Bodenheimer T, Lorig $\mathrm{K}$, Holman H, Grumbach $\mathrm{K}$. Patient self-management of chronic disease in primary care. JAMA 2002; 288(19): 2469-2475.

30. Fried TR, Tinetti ME, lannone L. Primary care clinicians' experiences with treatment decision making for older persons with multiple conditions. Arch Intern Med 2011; 171(1): 75-80

31. Bower P, Macdonald W, Harkness E, et al. Multimorbidity, service organization and clinical decision making in primary care: a qualitative study. Fam Pract 2011; 28(5): 579-587.

32. National Institute for Health and Clinical Excellence. Acute kidney injury: draft scope. London: NICE, 2011

33. May C, Montori VM, Mair FS. We need minimally disruptive medicine. BMJ 2009 Aug 11;339:b2803. doi: 10.1136/bmj.b2803. 